\title{
O IMPACTO AMBIENTAL DO USO DE AGROTÓXICOS NO MEIO AMBIENTE E NA SAÚDE DOS TRABALHADORES RURAIS
}

\author{
Tanny Oliveira Lima Bohner ${ }^{1}$ \\ Luiz Ernani Bonesso Araújo² \\ Toshio Nishijima ${ }^{3}$
}

\begin{abstract}
RESUMO
Agrotóxicos são produtos químicos utilizados na agricultura, com o objetivo de combater pragas e organismos patógenos que possam comprometer a produção agrícola. No entanto, utilização destes insumos não só é responsável pela contaminação ambiental, mas também é a causa de muitos problemas de saúde pública, pois quando aplicados inadequadamente prejudicam o meio ambiente e a saúde dos trabalhadores rurais e dos consumidores. A partir do reconhecimento dos efeitos negativos de uma potencial contaminação por agrotóxicos à saúde da população local e ao meio ambiente, este trabalho tem como objetivo avaliar o nível de conhecimento dos usuários de produtos químicos na prática da agricultura. Para tanto, foram aplicados questionários aos agricultores locais, abordando o nível de conhecimento e o grau de compreensão a respeito da legislação, do receituário agronômico, biossegurança, aplicação e descarte de agroquímicos. A análise dos resultados demonstrou que a maioria dos agricultores não lê sempre o receituário agronômico e não compreende totalmente as informações contidas na bula, as tarjas e os desenhos presentes nos rótulos dos agrotóxicos. Além disso, a maior parte dos agricultores faz o uso parcial dos Equipamentos de Proteção Individual. Em relação ao armazenamento dos agrotóxicos, grande parte dos agricultores revelou não sinalizá-los adequadamente. E mais, muitos não sabem diferenciar um agrotóxico contrabandeado de um produto legal. Portanto, são necessárias decisões urgentes para o esclarecimento e conscientização dos agricultores, instruindo e alertando a população sobre riscos eminentes de toxidez e informando a respeito das informações referentes aos agrotóxicos, bem como a utilização correta dos defensivos agrícolas, segundo as normas de biossegurança.
\end{abstract}

Palavras-chave: agrotóxicos, contaminação, meio ambiente, saúde

\section{INTRODUÇÃO}

A produção agrícola pode ser afetada por diversas pragas, como insetos, patógenos e plantas invasoras. Para combater estes organismos, são utilizados produtos químicos, como inseticidas, fungicidas, acaricidas, nematicidas, bactericidas e vermífugos (ALVES FILHO, 2002; SANTOS e PHYN, 2003).

\footnotetext{
${ }^{1}$ Acadêmica do curso de Agronomia e especialista em Educação Ambiental pela Universidade Federal de Santa Maria - UFSM. E-mail: tanny.bohner@ hotmail.com

2 Professor de Direito Ambiental e Agrário do Curso de Direito da UFSM e do Curso de Especialização em Educação Ambiental da Universidade Federal de Santa Maria, RS, Brasil. E-mail: luiz.bonesso@gmail.com.

3 Professor do curso de Agronomia, Engenharia Florestal e do Curso de Especialização em Educação Ambiental da Universidade Federal de Santa Maria. Email: Toshionishijima@ gmail.com
} 

Revista Eletrônica do Curso de Direito - UFSM

ISSN 1981 - 3694
I CONGRESSO INTERNACIONAL

DE DIREITO AMBIENTAL E ECOLDGIA POLITICA - UFSM

III SEMINÁRII ECDLOGIA

POLIITICA

E DIREITO NA AMÉRICA LATINA

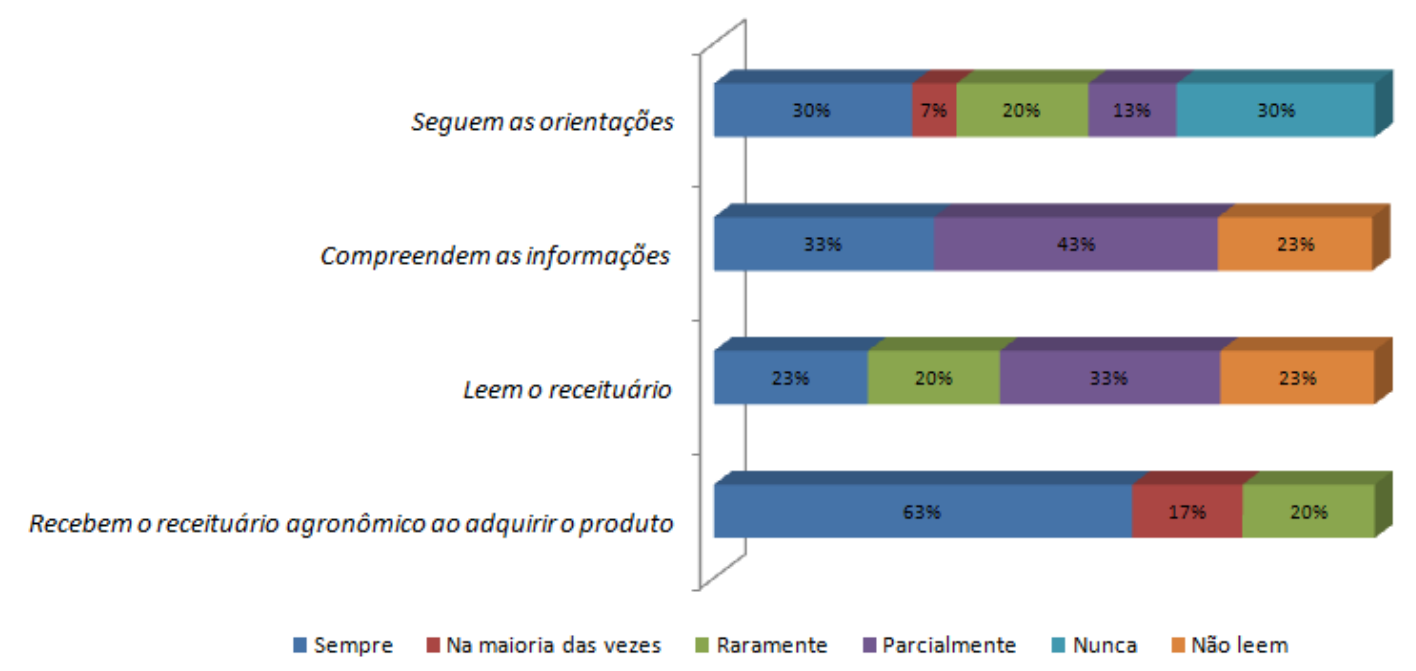

Figura 1. Informações referentes à compreensão do receituário agronômico pelos agricultores. Chapecó, SC, 2011.

Dos 83,3\% agricultores que lêem a bula dos agrotóxicos, apenas 30\% compreendem todas as informações e $54 \%$ as seguem, o que pode ser constatado na figura 2 .

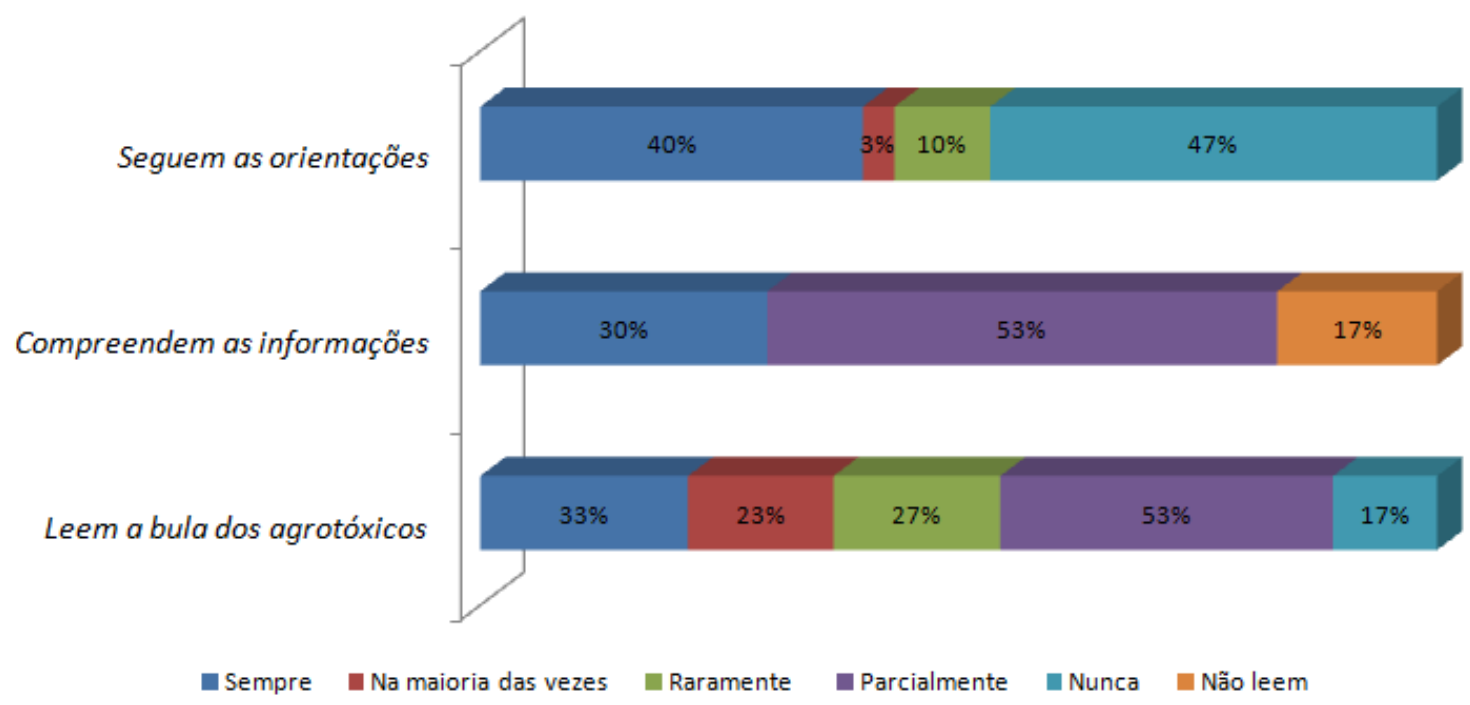

Figura 2. Compreensão da bula dos agrotóxicos pelos trabalhadores agrícolas. Chapecó, SC, 2011. 
III SEMINÁRII ECDLOGIA

De acordo com a figura 3, a maioria dos participantes observa os desenhos e as tarjas representados nos agrotóxicos. Contudo, apenas 36,7\% revelam compreender totalmente as tarjas, e $20 \%$ entendem todos os desenhos.

Na concepção de Garcia (2005), um dos fatores responsáveis pelo uso inadequado de agrotóxicos é a não observação das orientações e instruções contidas nos rótulos e bulas dos produtos.

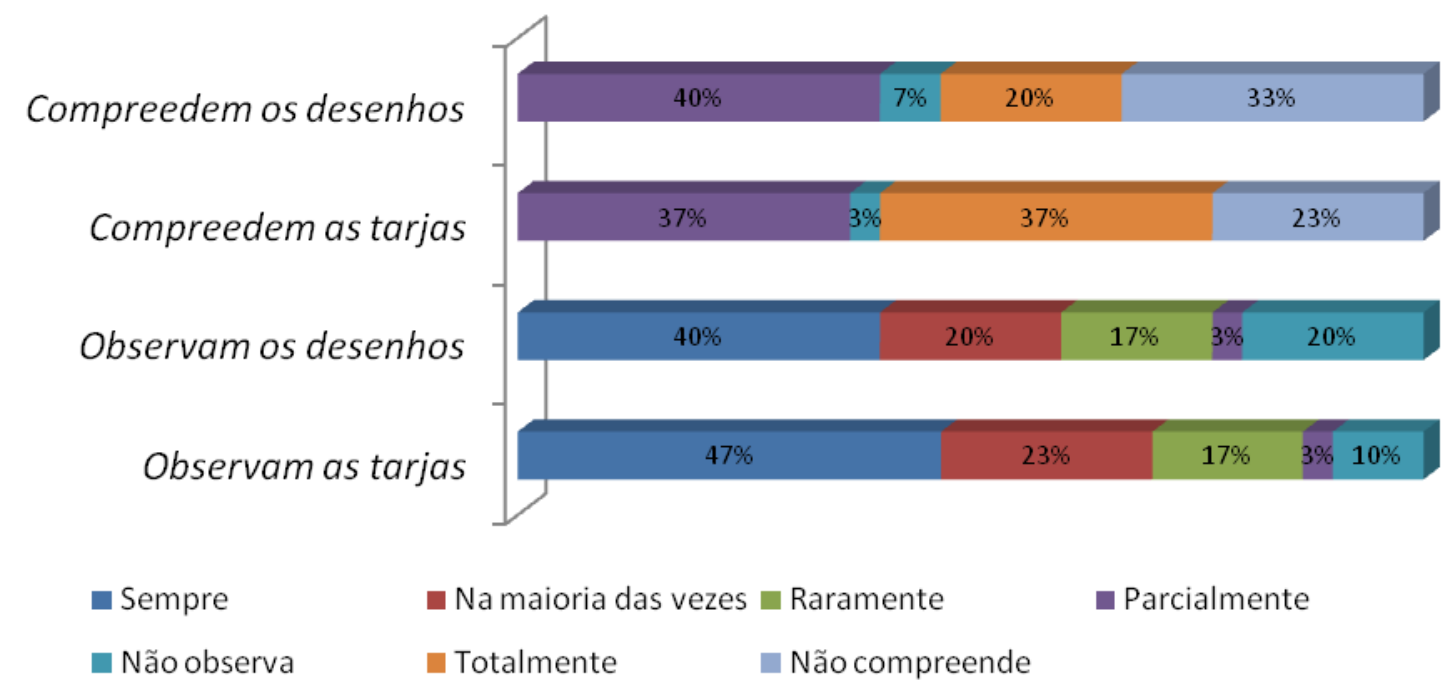

Figura 3. Compreensão dos agricultores acerca dos desenhos e tarjas presentes nos rótulos dos agrotóxicos. Chapecó, SC, 2011.

Oliveira-Silva et al (2001) constatou em sua pesquisa que 64\% dos agricultores entrevistados no município de Magé (RJ) não praticavam a leitura dos rótulos dos produtos. Segundo o autor, os níveis de escolaridade aliados à linguagem técnica das informações contidas nas embalagens justificam a deficiência na compreensão das informações pelos trabalhadores rurais. Do mesmo modo, Siqueira et al (2008) define a linguagem pouco acessível como um entrave ao entendimento dos usuários.

De todos os entrevistados, $83,7 \%$ utilizam algum tipo de equipamento de proteção individual (EPI), enquanto que 16,3\% não utilizam nenhum tipo de EPI. Deste total que utiliza EPI's, $99 \%$ dos produtores usam botas; 95\% usam máscaras; 87,5\% usam luvas; 63,6\% usam calça e jaleco; 51,7\% usam boné; 43,7\% usam avental e 43,7\% usam viseira (Figura 4). 


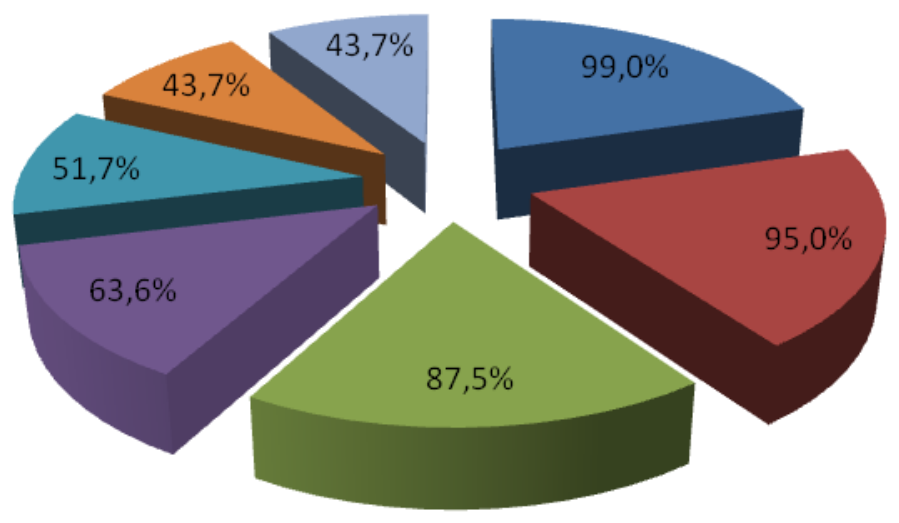

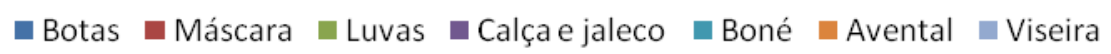

Figura 4. Percentual de equipamentos de Proteção Individual utilizados pelos produtores. Chapecó, SC, 2011.

Silva (2001) verificou que, mesmo os agricultores que utilizam EPIs, nem sempre o empregam adequadamente, ou o fazem em partes. Em seu trabalho, metade dos entrevistados relataram fazer o uso apenas da bota e do chapéu, fato constatado também por Castro et al (2011). Trabalhadores rurais entrevistados por Soares et al (2003) atribuem esta deficiência ao desconforto, dificuldade de locomoção e excessivo calor do EPI.

Alguns estudos estabelecem relações entre a exposição aos agrotóxicos e prejuízos à saúde humana. Em Minas Gerais, Soares et al (2003) constatou através de análise sanguínea que $50 \%$ dos trabalhadores entrevistados estavam intoxicados.

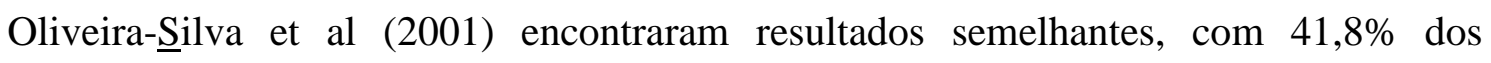
trabalhadores infectados. Ambos os autores identificaram como fatores de risco o não uso de EPI's e o curto intervalo de tempo entre as recorrentes manipulações dos agrotóxicos. Soares et al (2003) também relaciona estes fatores e afirma ainda que o agricultor desprotegido tem as chances de intoxicação aumentadas em $72 \%$, e os que entram em contato com o produto em um intervalo de tempo menor que 15 dias tem $43 \%$ a mais de chances de intoxicação. 


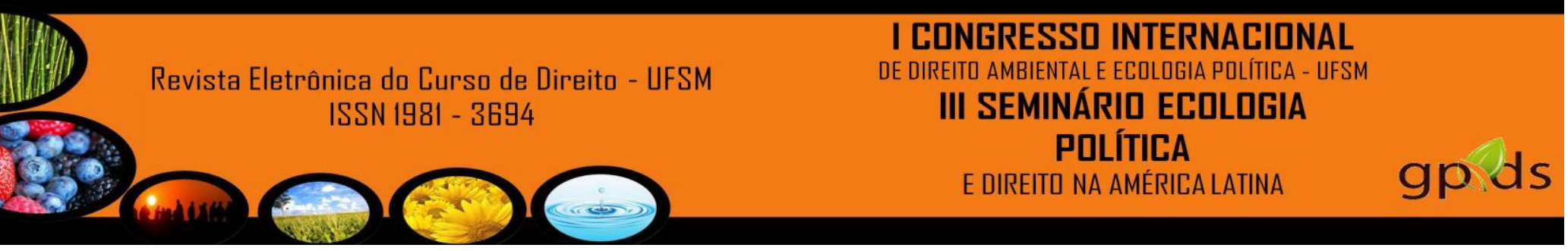

Peres et al (2004) ressalta que, segundo entrevistados, os principais sintomas de intoxicação são dor de cabeça, dor de barriga e tontura. Pires et al (2005) relaciona ainda as atividade agrícolas às intoxicações e tentativas de suicídio pela exposição a agrotóxicos na microrregião de Dourados (MS), principalmente durante a safra de verão.

A figura 5 ressalta que a maioria dos entrevistados frequentemente considera as condições climáticas, o horário de aplicação e a regulagem dos equipamentos.

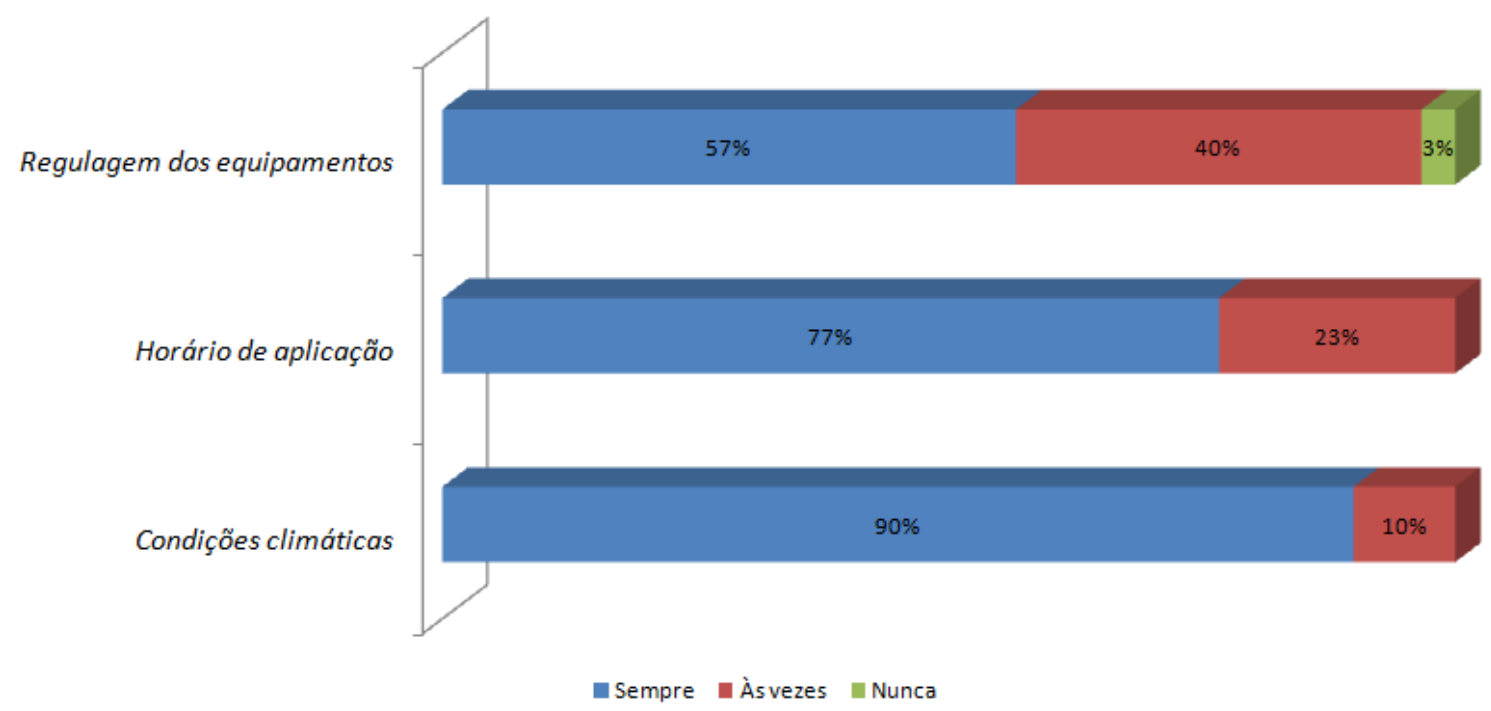

Figura 5. Fatores considerados pelos agricultores no momento da aplicação dos agrotóxicos. Chapecó, SC, 2011.

Recena et al (2006) relacionou a intoxicação dos agricultores, não só à ausência de equipamentos de proteção individual e à toxidade dos produtos, mas também às práticas de baixa tecnologia. Segundo Silva (2001), o despreparo da população para a manipulação destas substâncias e a falta de apoio técnico contribuem para a exposição da população aos pesticidas.

A maior parte dos entrevistados realiza o armazenamento destes produtos em local fechado e à uma distancia segura de crianças, alimentos e fontes de água. Entretanto, $60 \%$ revelaram não sinalizá-los adequadamente, como demonstra a figura 6. 
III SEMINÁRIO ECDLOGIA

POLÍTICA

E DIREITO NA AMÉRICA LATINA

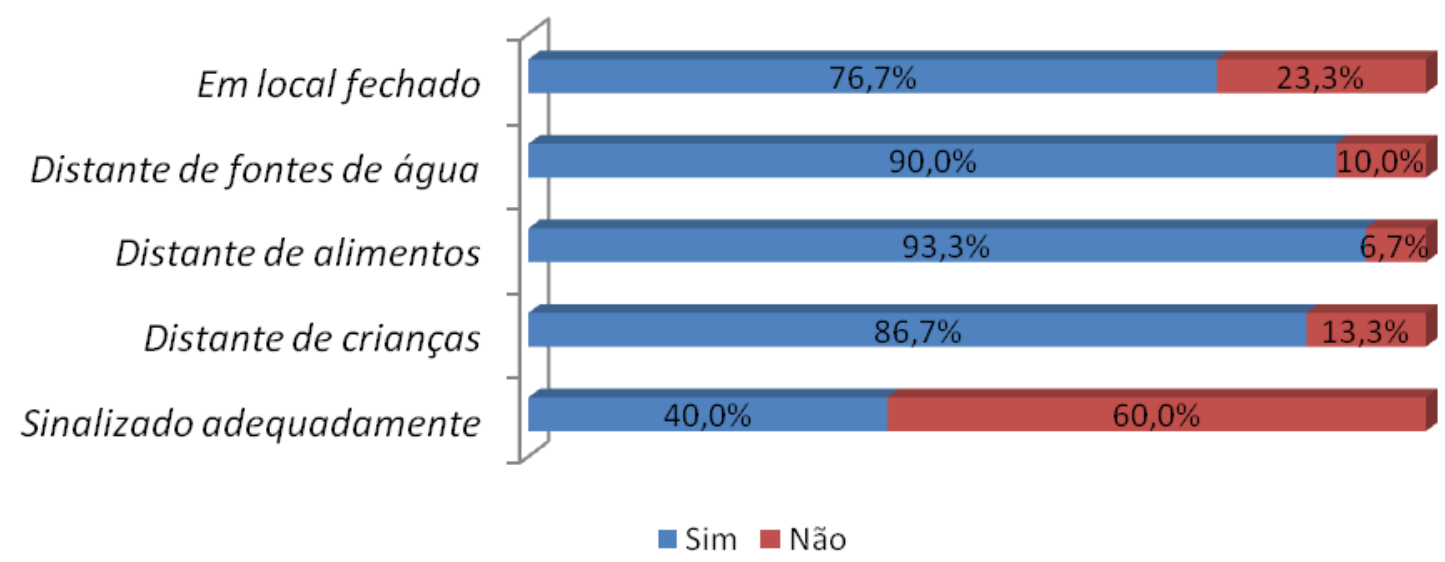

Figura 6. Fatores de segurança considerados na definição do local de armazenamento dos agrotóxicos. Chapecó, SC, 2011.

Castro ET AL (2011) analisou o uso de agrotóxicos em dois assentamentos de reforma agrária em Russas, CE, e verificou que a maior parte dos entrevistados armazenava os agrotóxicos em suas residências ou o depositavam fora, junto a outros materiais, sem definir uma distância mínima de segurança.

Posteriormente à aplicação dos agrotóxicos, grande parte dos entrevistados toma os cuidados necessários em relação à lavagem dos equipamentos de proteção individual e higiene pessoal, o que é evidenciado na figura 6.

Em relação à lavagem das embalagens vazias, Quintela (2004) relaciona esta prática com a diminuição dos riscos de contaminação, proteção do meio ambiente e ainda permite o aproveitamento integral do produto.

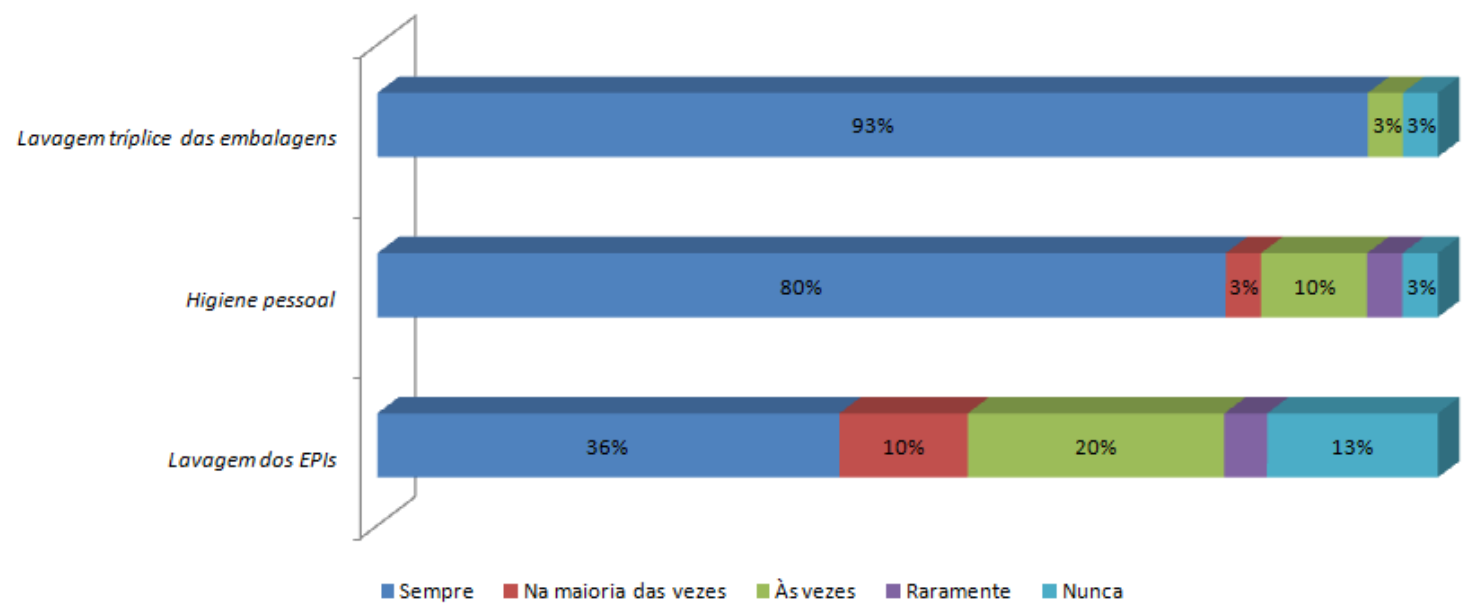


Tem conhecimento da comercialização de produtos contrabandeados

Diferenciam agrotóxicos contrabandeados de agrotóxicos legais

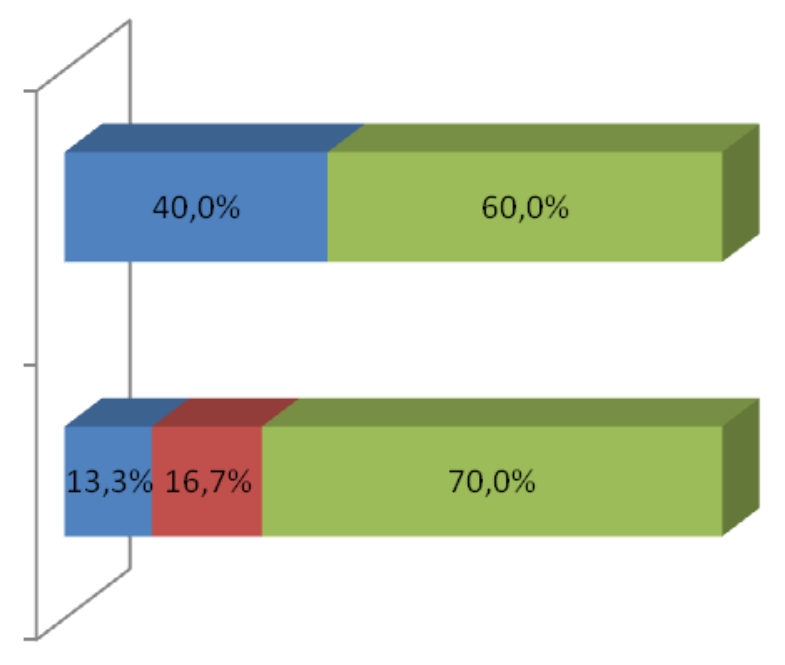

- Sim $\square$ Sim, mas tem dificuldades $\square$ Não

Figura 9. Conhecimento dos trabalhadores agrícolas em relação à produtos contrabandeados. Chapecó, SC, 2011.

\section{CONCLUSÃO}

Foi possível concluir que o conhecimento dos trabalhadores rurais referente aos aspectos relacionados à compreensão das informações referentes à manipulação, armazenamento, descarte e à legislação fitossanitária é inadequado.

Apenas 23,3\% dos trabalhadores rurais costumam ler sempre o receituário agronômico e $30 \%$ compreendem todas as informações contidas na bula dos agrotóxicos. Somente $36,7 \%$ revelam compreender totalmente as tarjas, e $20 \%$ entendem todos os desenhos presentes nos rótulos dos agrotóxicos. Além disso, 83,3\% dos agricultores utiliza algum tipo de EPI, no entanto o fazem parcialmente. Em relação ao armazenamento dos agrotóxicos, $60 \%$ revelaram não sinalizá-los adequadamente. E mais, 70\% não sabem diferenciar um agrotóxico contrabandeado de um agrotóxico legal.

Ante o exposto, são necessárias decisões urgentes para o esclarecimento e conscientização dos agricultores, instruindo e alertando a população sobre riscos eminentes de toxidez e informando a respeito das informações referentes aos 


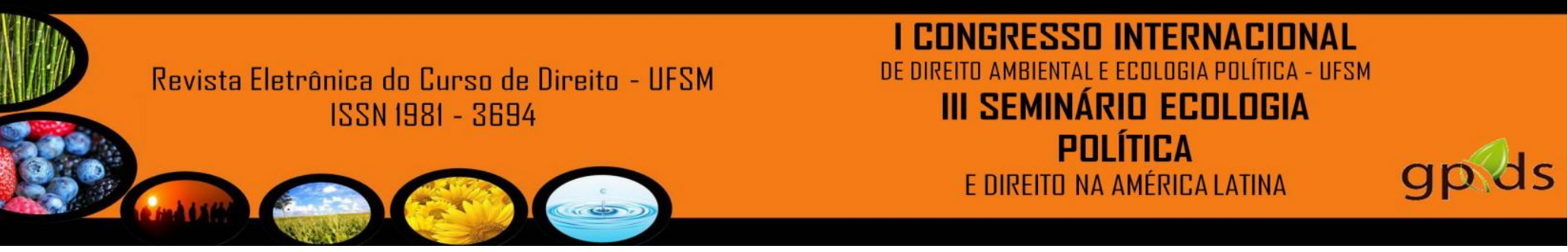

agrotóxicos, bem como a utilização correta dos defensivos agrícolas, segundo as normas de biossegurança.

\section{REFERÊNCIAS BIBLIOGRÁFICAS}

ABRAMOVAY, R.Construindo a ciência ambiental. São Paulo: Annablume, 2002.

ALVES FILHO, J. P. Uso de agrotóxicos no Brasil: controle social e interesses corporativos. São Paulo: Annablume, 2002.

BEDOR, C. N. G. et al. Vulnerabilidades e situações de riscos relacionados ao uso de agrotóxicos na fruticultura irrigada. São Paulo: Rev. bras. Epidemiol. vol. 12, n. 1, p. 39-49, 2009

BRIGANTE, J.; ESPÍNDOLA, E. L. G.; POVINELLI, J.; ELER, M. N.; SILVA, M. R. C.; DORNFELD, C. B.; NOGUEIRA, A. M. Avaliação ambiental do rio MogiGuaçu:resultados de uma pesquisa com abordagem ecossistêmica. São Carlos: Rima, 2002.

1.1. CASTRO, M. G. G. M.; FERREIRA, A. P.; MATTOS, I. E.; Uso de agrotóxicos em assentamentos de reforma agrária no Município de Russas (Ceará, Brasil): um estudo de caso. Epidemiologia e Servicos de Saúde v.20 n.2 Brasília jun. 2011

FOSTER, S.; Hirata R.; Gomes, D.; D'Elia, M.; Paris, M. Proteção da qualidade da água subterrânea: um guia para empresas de abastecimento de água, órgãos municipais e agências ambientais. São Paulo: SERVMAR, 2006.

GONSALVES, P. E. Maus hábitos alimentares. São Paulo:Agora, 2001.

LAABS, V.; AMELUNG, W.; PINTO, A.; ZECH, W. Fate of pesticides in tropical soils of Brazil under field conditions. Journal of Environmental Quality, ${ }^{\circ} 31$, p. 256-268, 2002.

MIRANDA, A. C.; MOREIRA, J. C.; CARVALHO, R.; PERES, F. Neoliberalismo, o uso dos agrotóxicos e a crise da soberania alimentar no Brasil. Ciência Saúde Coletiva, Rio de Janeiro, v.12,n. 1, p. 15-24, 2007.

OLIVEIRA-SILVA, J. J., et al. Influência de fatores socioeconômicos na contaminação por agrotóxicos, Brasil. Revista de saúde pública, v. 35, n. 2, p. 130-135, Magé-RJ, 
